This PDF is a selection from a published volume from the National Bureau of Economic Research

Volume Title: Science and Engineering Careers in the United States: An Analysis of Markets and Employment

Volume Author/Editor: Richard B. Freeman and Daniel L. Goroff, editors

Volume Publisher: University of Chicago Press

Volume ISBN: 0-226-26189-1

Volume URL: http://www.nber.org/books/free09-1

Conference Date: October 19-20, 2005

Publication Date: June 2009

Chapter Title: Patterns of Male and Female Scientific Dissemination in Public and Private Science

Chapter Author: Kjersten Bunker Whittington

Chapter URL: http://www.nber.org/chapters/c11622

Chapter pages in book: (p. 195 - 228) 


\title{
Patterns of Male and Female Scientific Dissemination in Public and Private Science
}

\author{
Kjersten Bunker Whittington
}

\subsection{Introduction}

Information on the patenting and publishing activity of scientists and engineers has long been an interest among scholars of science and technology. Publishing transmits valuable knowledge and resources to other scientists, both in the academy and in industry, while patenting is thought to spur innovation through economic and proprietary incentives. Traditionally, scientists within academia have primarily published, shying away from pursuing economic ends through patenting or other marketable ventures, while industrial scientists have predominantly pursued commercial goals. Aided by federal and state promotion as well as university infrastructure, the organization of scientific research within universities and industrial firms has undergone a sea change in the past two decades. Academic scientists are now commonly involved in a variety of commercial activities, including patenting, licensing, start-up incubation, and firm founding, especially in the life sciences (Rosenburg and Nelson 1993; Cohen, Florida, and Goe 1994; Kleinman and Vallas 2001; Owen-Smith and

Kjersten Bunker Whittington is an assistant professor of sociology at Reed College.

This research is based upon work supported by a National Bureau for Economic Research (NBER) Dissertation Fellowship from the Science and Engineering Workforce Project, as well as an Association for Institutional Research (AIR) grant. Any opinions, findings, conclusions, or recommendations expressed in this publication are those of the author and do not necessarily reflect the views of NBER or AIR. Analyses in this work are conducted with restricted National Science Foundation SESTAT data, made available to researchers through the U.S. government (http://sestat.nsf.gov). The use of restricted data does not imply NSF endorsement of the research methods or conclusions contained in this report. I wish to thank Walter Powell, Jason Owen-Smith, Laurel Smith-Doerr, Michael Rosenfeld, Cecilia Ridgeway, Justine Tinkler, and Stefanie Mollborn for their helpful comments and feedback on this project. Any remaining errors are, of course, my own. 
Powell 2001). At the same time, in some sectors there is much greater involvement in basic research by industry (Powell and Owen-Smith 1998). Research suggests that increases in academic-industry relations are shaping faculty careers in new directions, and altering the standards by which occupational success and reward are determined (Etzkowitz 1993; Packer and Webster 1995; Owen-Smith and Powell 2001).

There is evidence that commercialization may be a new arena for disparities between men and women in scientific productivity. Recent work indicates that academic women are less likely to become involved in commercial activity than men (Whittington and Smith-Doerr 2005; Ding, Murray, and Stuart 2006; Whittington 2007; Whittington and SmithDoerr 2008). But past studies have yet to examine scientists from a variety of disciplines (most focus on the life sciences) or consider how men's and women's involvement in the joint activities of public and private science arise. In addition, much of the research on men and women in science leaves the actions and rationale of industry scientists unaddressed (but see Whittington [2007]). Given that the rate of women's entrance in the industrial labor force has eclipsed that of men in the past few decades (Long 2001), now more than ever it is relevant to consider industrial scientists, and to compare the nature of sex disparities across sectors and work environments.

I present a two-part analysis to address patterns of men's and women's dissemination in patenting and publishing activities (separately, together, or not at all) across sectors and disciplines. The first analysis uses loglinear modeling of a national sample of scientists and engineers to address the association between sex, discipline, employment sector, and involvement in scientific dissemination. I test the extent to which sex disparities in productivity are created and maintained by sorting mechanisms (i.e., the extent to which men and women scientists are differentially located in higher producing sectors or disciplines), as well as through organizational settings after controlling for sex distributions. In the second analysis I explore the ways in which various organizational contexts may differentially influence men and women scientists. I contrast two basic forms of organization-academic hierarchy, and what is sometimes called the "network form" of organization (Powell 1990; Podolny and Page 1998). I present network visualizations of coinventor collaborations between life science inventors working in the academy, public research organizations, and biotechnology firms, and address how the structure of science within each sector may contribute to sex disparities in productivity. Assessing the effects of organizational context on multiple forms of dissemination is of great importance as scholars begin to sort out the contemporary pushes, pulls, and constraints operating on women scientists in an era where commercial and academic science are much more closely linked. 


\subsection{Theoretical Background}

\subsubsection{Gender and Productivity}

Past research on scientific women documents their many structural and socialized constraints (for reviews of the literature, see Long and Fox [1995]; and Xie and Shauman [2003]). Women are less likely to participate in science, have less prestigious positions, and have received less recognition than men (Cole and Zuckerman 1984; Zuckerman 1991). Studies show that at all levels, there is a great disparity in the career attainments and opportunities of women scientists (Etzkowitz, Kemelgor, and Uzzi 2000). These disparities extend into accounts of research productivity as well, as women scientists have traditionally published less than men in the sciences (Cole 1979; Fox 1983; Cole and Zuckerman 1984; Long 2001; Xie and Shauman 2003).

Given the current climate of science, it is important to consider sex disparities in commercial involvement as well as publishing. Research shows that women faculty do not sit on scientific advisory boards at the same rate as men scientists, and at the highest level of commercial involvement, they make up miniscule percentages of company founders (Ding, Murray, and Stuart 2006; Stuart and Ding 2006; Murray and Graham 2007). Sex disparities also exist in rates of academic patenting. Women faculty engage in patenting behavior at a decreased rate than male scientists, and produce less patents overall (Morgan, Kruytbosch, and Kannankutty 2001; Whittington and Smith-Doerr 2005; Whittington 2007; Whittington and SmithDoerr 2008).

Patents are an increasingly available academic activity, and like publishing, can be an important signal of scientists' research capabilities; thus a determinant of career outcomes. In addition, commercial involvement may bring academic scientists substantial increases in research funding, access to better research tools and equipment, potentially large gains in personal wealth, and an increased attractiveness to potential graduate students, postdocs, and other academic and industry collaborators. While in industry commercial output is often an expected productivity outcome, it remains a way for scientists to prove their company worth and value. Whether or not, and the degree to which, a scientist is active in publishing or patenting are particularly defining signals of his or her research and development goals and opportunities.

Scientists are increasingly pursuing academic and industrial activities hand in hand. Stephan et al. (2007) find that publishing is positively related to patenting, thus one form of productivity does not seem to preclude the other (but see Owen-Smith and Powell [2001]; Bonaccorsi, Daraio, and Simar [2006]). In addition, if an academic life scientist's colleagues, co- 
authors, or department chair engage in commercial behavior, it significantly increases the chances that the scientist will as well (Stuart and Ding 2006; Bercovitz and Feldman Forthcoming). Research also suggests that patenting is strongly affected by the institutional environments where academic science takes place. Stephan et al. (2007) show that the number of patent applications is higher for those working in universities than house medical institutions and research institutes. Ding, Murray, and Stuart (2006) find evidence that university support for patenting plays an important role in scientists' propensity to patent. Like publishing, the conclusion is that context matters.

Researchers have proposed many explanations for the productivity differences in publishing between men and women, yet early research efforts that focused on individual status characteristics have been unable to fully account for variation in publication output (Zuckerman 1991; Long and Fox 1995; Ward and Grant 1995). Characterized most famously by Cole and Zuckerman (1987), this inequity has traditionally been referred to as the gender "productivity puzzle." Much of the early research, however, fails to consider how resource distribution, job placement, and the structure of academic work is gendered. Organizational context likely plays an important role in gender equality, as successful scientific work relies on equal access to facilities and funds, available help, and a supportive research environment (Fox 1991, 2001). Indeed, in recent work, Xie and Shaumann $(1998,2003)$ are able to render much of the direct effects of sex on publication productivity insignificant by taking into account organizational positions and resources. They suggest that the traditional productivity puzzle should be replaced with a new puzzle to explain differences in resources and structural characteristics.

The correlates and variations of the sex gap in patenting are not welldocumented. In addition, while numerous studies have contributed to our understanding of inequality among scientists, most have concentrated on either one type of science or another, combined similar sciences together (often in an attempt to increase the small percentages of women in their sample), or controlled for discipline or employment sector effects irrespective of their joint interaction with sex. Furthermore, few analyses have concentrated on how these contexts may affect men and women scientists differentially. Lastly, by focusing solely on faculty members, previous research neglects to address how the existing organization of academic life compares with that of other science and technology sectors. These issues are particularly important as there has been a slow but steady increase in the percentage of scientists working beyond the academic sector (Long 2001).

\subsubsection{Gender, Scientific Dissemination, and Organizational Context}

Historically, industry has been seen as separate from and less prestigious than academia (Caplow and McGee 1961), yet it has also provided some 
women with favorable workplace incentives (such as flexibility and higher mobility) not present in the academy (Aisenburg and Harrington 1988; Long and Fox 1995). In the past there has been speculation that women make a tradeoff in prestige for the slight advantages available in industry (Etzkowitz, Kemelgor, and Uzzi 2000). Recently, scholars are recognizing that careers outside the academy are growing in numbers and in prestige, as well as offering increased incentives for scientists, who choose to leave the ivory tower (Rabinow 1996).

Whether this changing context has had a differential effect on men and women scientists is unclear, as measures of inequality among industrial scientists are lacking. However, Smith-Doerr (2004) shows that men and women tend to hold comparable management positions in industrial biotechnology firms. Past research by Long, Allison, and McGinnis (1993) shows a causal relationship between academic rank and dissemination, with higher-producing scientists receiving more returns to career advance. We might expect that similar processes may be acting upon industrial scientists, and as such, sex differences in involvement among them may be smaller than their academic counterparts. To the extent that sex differences in research productivity are the result of the different positions women hold rather than differences in capability or motivation, one can expect the sex gap in dissemination involvement to vary across sectors as well.

The effects of location and context may also vary by the type of science, as resources and opportunities to publish or patent operate differently among disciplines. Commercialization in the physical sciences (comprised mostly of optics and solid-state applications) has more distant and less direct economic payoffs than the life sciences, where research results translate into new medicines with some urgency and for considerable profit. In addition, the public drive to finance and invest in physical science research is considerably less than that of the life sciences. Computer science faces a different issue. Its technology moves at a much faster pace in both discovery and development than other sciences, and the average three-year lag between filed and issued inventions can be problematic. Often computer science and similar fields resort to other methods of dissemination such as trade secrets, publishing, or copyright to preserve property rights and/or transmit new knowledge. Also relevant is the fact that the proportion of women across scientific fields varies. Women make up a much higher percentage of life and computer scientists than physical scientists and engineers. In this case, assessing the sorting of scientists across sectors and disciplines would provide useful information about the nature of sex disparities in productivity across sectors.

In as much as patenting varies by sector and discipline, dissemination is also influenced by the norms and characteristics of the working environment. The broad contexts of academic and industrial work also likely have differing effects on men and women (Fox 1991, 2000). The analyses in this 
chapter build upon my previous research, which finds sex disparities in commercialization among life scientists to vary across work settings (Whittington and Smith-Doerr 2005; Whittington 2007; Whittington and Smith-Doerr 2008). Using a combination of career history data and patenting information for a sample of life scientists across a period of two decades, this work finds that women engage in and produce less commercial work than men. The degree of disparity remains relatively constant across time. Importantly, sex differences in commercial involvement are greatest in academia, where the percentage of men involved in patenting more than doubles that of women. Although women patent less than men in industry as well, it is a much smaller difference. ${ }^{1}$

This previous research provides a starting place to address how dissemination varies across sectors, but has several implications for future work. First, the focus on a sample of life scientists leaves the broader context of discipline unaddressed. It would be useful to address the extent to which sector- and discipline-level sorting mechanisms account for sex disparities in productivity. Second, while the focus of this research puts emphasis on the degree to which academic scientists are patenting, it does not address the extent to which industrial scientists publish, as well as joint involvement in patenting and publishing. In both public and private science, men and women who are involved in these dual activities possess an ability to speak to multiple domains of science, and to apply complementary application to their research. In this work, I argue that it is important to know the extent to which men and women are participating in both patenting and publishing, across all sectors and disciplines.

To this end, the first analysis addresses the relationship between organizational context and gender on a macro-level across three disciplines and three employment sectors. I present loglinear models of patenting and publishing activity using a nationally representative sample of doctoral recipients, for publishing as well as patenting. Specifically, I address the following questions: Does men and women scientists' propensity to patent and publish vary by type of science and employment sector? Is there a sex gap after controlling for the distribution of men and women into lower- or higher-producing sciences and sectors? In sum, what is the association between sex, discipline, employment sector, and involvement in scientific dissemination?

In the second analysis I explore the ways in which various organizational contexts may differentially influence men and women, highlighting the specific case of life scientists working in the Boston area, one of the most

1. However, among those involved in commercial activity, the quality and impact of women's commercial work remains the same or better than that of male scientists (as measured by forward and backward patent citations). 
active and fertile biotechnology clusters in the world (Owen-Smith and Powell 2004; Porter, Whittington, and Powell 2005). Using patenting data made available through the National Bureau of Economic Research (NBER) on U.S. inventors across time (Hall, Jaffe, and Trajtenberg 2001), I present network visualizations that depict inventor collaborations of university and industry life science inventors. I suggest how the structure of science within each sector may contribute to existing trends in sex differences in productivity. Combined, the two analyses have important implications for the effects of organizational context on men's and women's productivity.

\subsection{Patterns of Publishing and Patenting Across Sectors and Disciplines}

\subsubsection{Data}

To examine the relationship between scientific dissemination and sex, type of science, and employment sector, I analyze data from the $1995 \mathrm{Na}-$ tional Science Foundation's Survey of Doctoral Recipients (SDR). ${ }^{2}$ The SDR incorporates a complex survey design that stratifies respondents by scientific discipline, employment sector, receipt of a doctoral degree, and certain demographic variables. When weighted, SDR data characterizes a nationally representative population of individuals trained and/or working as scientists or engineers between 1990 and $1995 .^{3}$ The SDR includes scientists working across a variety of employment sectors and disciplines, making it a useful data set to address these research questions.

For this analysis I focus only on scientists whose principal work responsibilities include research and development. The SDR asked respondents to indicate the primary and secondary work activities on which they "spend the most hours during a typical work week." ${ }^{4}$ I restrict the sample of scientists to those who listed applied research, basic research, development, or design as their primary work activity. Limiting the sample to scientists who indicate that they spend the most time on research and development helps to reduce concern over unequal allocations of work activities

2. The SDR population consists of all individuals under the age of seventy-six who received a research doctorate in science or engineering from a United States institution prior to June 1994 and who resided in the United States as of April 1995.

3. All results and data presented here incorporate weighted sample statistics.

4. Scientists could choose from the following work activities: (a) accounting, (b) applied research, (c) basic research, (d) computer applications, programming, or system development, (e) development, (f) design of equipment, processes, or models, (g) employee relations including recruitment, training, or personal development, (h) managing and supervising, (i) production or operations, (j) professional services, (k) sales, purchasing, marketing, customer service, or public relations, (l) quality assurance, (m) teaching, or (n) other. 
among women and men in similar positions (for example, gender variations in teaching loads or committees, management responsibilities, etc.). ${ }^{5}$

\subsubsection{Measures}

Dissemination activity is measured by combining responses to two survey questions. Scientists were asked whether or not they had been named as an inventor on (a) a U.S. patent application and (b) as an author or coauthor on a peer-reviewed published paper, in the past five years. These two variables were combined to make one variable with four categories: (a) respondent neither published nor patented, (b) respondent published, but did not patent, (c) respondent patented, but did not publish, and (d) respondent both published and patented. ${ }^{6}$

Scientists are classified by what NSF terms "major employment sector," that is, two-year colleges, four-year colleges, government, or business/industry. Institutions designated as four-year colleges include baccalaureate and master's institutions, and Research I and II universities. The industrial sector includes private, for-profit companies, as well as scientists who are self-employed. Most scientists within the government sector are federal workers; however, state and local government scientists are included as well. For the purposes of this research, however, government is included largely as a control.

In addition, scientists are placed in one of six disciplines according to the type of science they perform in their current job. These categories are computer and mathematical sciences, life sciences, physical sciences, social sciences, engineering, and nonscientific occupations. For this analysis, I exclude scientists who work at two-year colleges, as well as those located in computer sciences, the social sciences, or in nonscience or nonengineering disciplines. Theoretically, I am mainly concerned with scientific occupations that produce research that is potentially patentable as well as publishable. Although publications may be common, nonscientific occupations and the social sciences are not oriented toward commercialization in the same way other sciences are (for example, only 0.4 percent

5. In addition, only scientists who are working full time are included in the sample. Parttime scientists may not have an equal opportunity to publish and patent to the same degree as compared to their full-time counterparts. The percentage of scientists who work part time while engaging in research and development as a primary work activity is small (3.6 percent of the sample $(\mathrm{N}=636)$. Models run with and without part-time scientists do not differ qualitatively. All coefficients have the same sign and significance, and magnitudes are negligibly different.

6. Across and within sectors, disciplines vary in their propensity to publish and patent. Using a measure of publications and patents accrued over a period of five years may seem stringent for some fields and too lengthy for others. Because this analysis controls for distributions across discipline and sector, however, it is possible to compare scientists within fields and sectors without having to choose a global average across fields. 
$[N=7]$ of social scientists in the sample patent). ${ }^{7}$ In computer science, the rate by which innovation moves often means that the lag between filed and issued patents will outlive the novelty of the invention. As such, patenting is a rarity for scientists in this discipline and data set (approximately 2 percent $[N=15]$ of the patenting academic sample).

Once all variables and constraints are taken into account, the final sample for this analysis consists of 10,144 scientists, 16.5 percent of whom are women. There are no missing data.

\subsubsection{Survey Statistics}

Table 6.1 presents weighted summary statistics on the sample's participation in publishing and patenting activities, broken down by employment sector. The table shows that scientists vary in their propensity to publish and patent. Involvement in commercial activity remains an activity pursued by a minority of the scientific population. The majority of all scientists, women and men, tend to have only published, if at all, between 1990 and 1995. Approximately 25 percent of the national population of scientific doctorates indicated that they had patented between 1990 and 1995. This percentage is heavily skewed by the higher rates of industrial patenting, however. About 14 percent of university scientists had patented in the period leading up to 1995, as compared with 39 percent of industrial scientists. ${ }^{8}$

As table 6.1 shows, men and women have similar preferences for patenting and publishing, although women's participation differs from that of men in a few notable areas. First, a higher percentage of women than men only publish. This is true in both academic and industrial settings, although industrial differences are larger. In addition, the 1995 SDR data echoes previous findings of commercial participation, which show that women participate less in patenting than men. Approximately 13 percent of women as compared with 21 percent of men patent. The proportion of academic men involved in patenting is about twice that of women academic scientists. In-

7. However, because women represent a greater percentage of social and behavioral scientists than they do in the natural, physical, and engineering sciences, it is important to know how the exclusion of this group may bias the analysis. The majority of social scientists publish only or disseminate nothing ( 54.5 percent and 44.7 percent, respectively), and differences between men and women are small (although higher in academia than industry). Because very few members of these groups have a propensity to patent, many cells in the contingency table are small in count or have no activity at all. This sparseness ultimately causes methodological problems in the stability of the loglinear models that cannot be resolved. While instable, models run with and without social scientists yield coefficients similar in sign, magnitude, and significance, and the substantive findings of this work remain the same.

8. Although not in the table, the three disciplines also vary somewhat in their propensity to publish and patent. Engineers are more likely than life or physical scientists to patent in the university ( 24 percent versus 13 percent and 12 percent, respectively), and physical scientists are slightly more likely to patent in industry than engineers and life scientists (46 percent versus 38 percent and 31 percent, respectively). Tables available from the author upon request. 


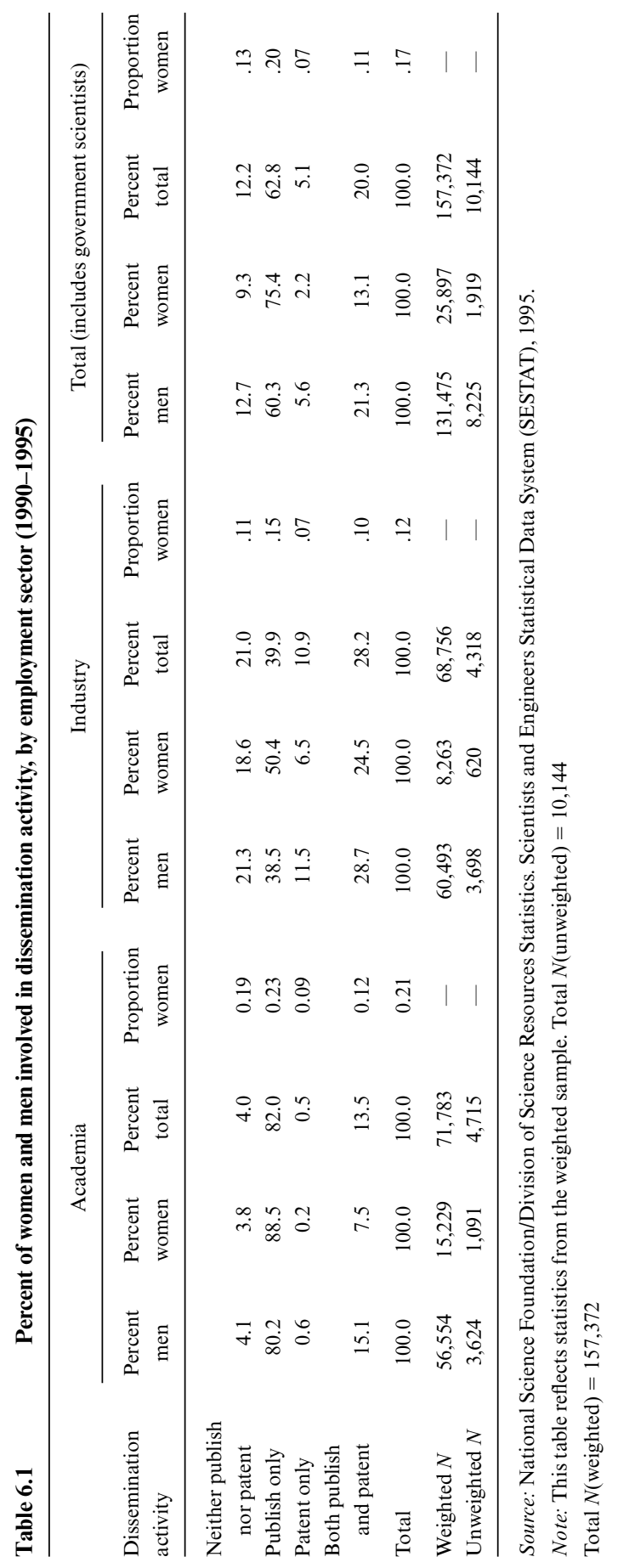


dustrial men and women scientists, on the other hand, appear to be more similar regarding commercialization. Women are only slightly less likely to participate in both patenting and publishing activities ( 25 percent versus 29 percent, respectively). The sector-level disparity in patenting involvement is roughly 50 percent higher in academia than in industry. Similar sector-level differences are seen when conceptualized as probability differences. The academic difference in probabilities between men and women is .076, compared to an industrial probability difference of .042 , which yields a 45 percent probability difference between the sectors.

The previous descriptive statistics suggest the need to further investigate the effects of men's and women's locations on dissemination activity. While women are less likely to engage in commercial behavior, once sorted by sector the dissemination trends among men and women scientists diverge. What effect does location have on women's dissemination activity once the distribution of men and women across disciplines is addressed? Moreover, how do documented sex disparities in dissemination change after accounting for location and organizational context? I turn to these questions in the following section.

\subsubsection{Methodology}

To study publishing and patenting behavior by sex, discipline, and employment sector, I use loglinear models that identify the associations among these variables independent of the marginal distributions of men and women across sciences and sectors. The primary objective of loglinear analysis is to determine if the distribution of counts among the cells of a table have an underlying structure. With the case of sex and dissemination, we can make several predictions about how the distribution of women and men in sciences and sectors may shape the degree to which women participate in various scientific dissemination activities.

This methodology is both useful and necessary for this type of analysis because it permits the modeling of relationships between two or more categorical variables. Rather than looking solely at the effects of each variable on a single outcome, this method is especially practical for this analysis because it allows for the complexities of association linkages among all of the variables. Thus, loglinear modeling accounts for the interrelationships between science, sector, sex, and dissemination. Importantly, this method is also able to estimate the effects of multiple-order interactions in conjunction with and controlling for the effects of other multiple-order interactions. $^{9}$

To examine these relationships, the scientific dissemination table was

9. One possible reason for the lack of research addressing joint program and sector effects on gender and dissemination is the methodological difficulty of multiple third-order interactions. Loglinear analysis provides a way to account for these multi-level interactions simultaneously. 
cross-classified by sex, employment sector, and discipline. There are 72 cells in the data set $(4$ [dissemination] $\times 2$ [sex] $\times 3$ [employment sector] $\times$ 3 [discipline]). Table 6.2 presents the seven nested models in this analysis. In simplified hierarchical terms, they can be presented as follows:

(1) $\operatorname{Ln}(U)=$ Constant + Error

(2) $\operatorname{Ln}(U)=$ Model $1+$ patpub + sex + discipline + empsectr

(3) $\operatorname{Ln}(U)=$ Model $2+$ patpub $\times$ discipline + patpub $\times$ empsectr + discipline $\times$ empsectr + patpub $\times$ discipline $\times$ empsectr

(4) $\operatorname{Ln}(U)=$ Model $3+$ sex $\times$ patpub

(5) $\operatorname{Ln}(U)=$ Model $4+\operatorname{sex} \times$ empsectr $\times$ discipline

(6) $\operatorname{Ln}(U)=$ Model $5+\operatorname{sex} \times$ patpub $\times$ discipline $+\operatorname{sex} \times$ patpub $\times$ empsectr

(7) $\operatorname{Ln}(U)=\operatorname{sex} \times$ patpub $\times$ empsectr $\times$ discipline

where only the highest-order terms are listed, and the lower-order terms are assumed. Here, $U$ is the predicted number of scientists, discipline is the scientific discipline, empsectr is the employment sector, patpub is patenting and publishing activity, and sex is the whether the respondent is a man or a woman.

While the loglinear model framework may seem foreign, logistic regression equivalency is possible for some loglinear models depending on the relationship between the dependent model and the predictor terms. For example, the multinomial equivalencies for the final two models above take the following form:

(6) Multinomial Logit(patpub) $=$ Constant + sex + discipline + empsectr

(7) Multinomial Logit(patpub) $=$ Constant + sex $\times$ empsectr $\times$ discipline

where only the highest-order terms are listed, and the lower-order terms are assumed. Because loglinear methodology does not assume a specific dependent variable but rather predicts cross-classified cell counts, it gives more flexibility to explore the relationships between all and various combinations of variables in the model.

\subsubsection{Gendered Dissemination across Sectors and Disciplines}

Table 6.2 presents the results from a series of loglinear models, in which the associations between gender, discipline, employment sector, and dissemination activity are estimated from the data. Models 1 and 2 in table 6.2 account for the constant-only model and the direct effects of the variables. The direct effects model accounts for dissemination, sex, type of science, and employment sector without making any assumptions about the relationships between the variables. The likelihood-ratio (LR) chi-square for model 2 is 4,903 with 63 degrees of freedom. As is to be expected, this model 
Table 6.2

Loglinear models of scientific dissemination, sex, discipline, and employment sector, 1990-1995

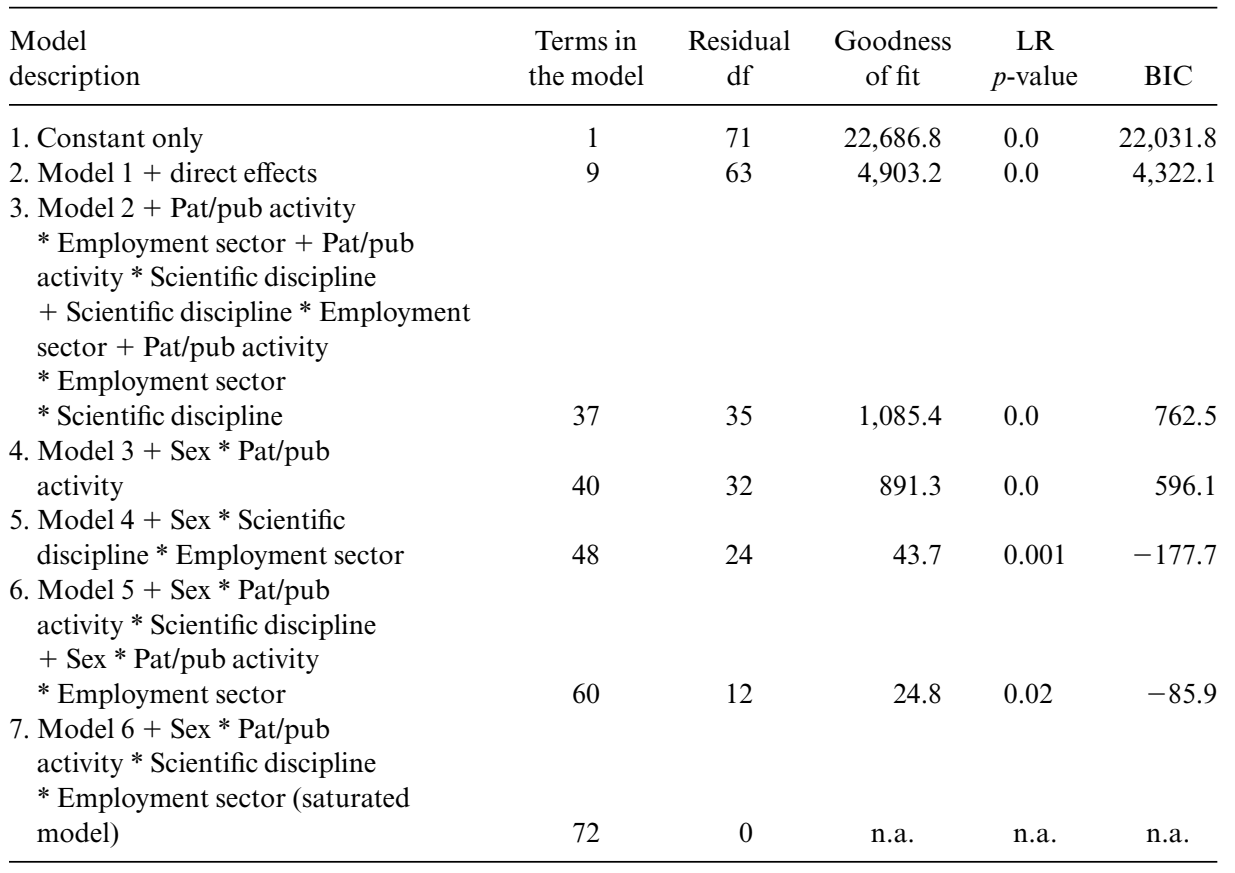

Source: National Science Foundation/Division of Science Resources Statistics. Scientists and Engineers Statistical Data System (SESTAT), 1995.

Notes: $\mathrm{df}=$ degrees of freedom; $\mathrm{LR}=$ likelihood-ratio; $\mathrm{BIC}=$ Bayesian Information Criterion; $\mathrm{n} . \mathrm{a} .=$ not applicable.

fits very poorly by both the likelihood ratio test and by the Bayesian Information Criterion (BIC).$^{10}$ This is not surprising because model 2 makes the unlikely assumption that scientists are distributed evenly across sectors and programs, and disseminate equally without effects from these areas.

The third model adds twenty-eight terms to account for the effects of differential dissemination rates across disciplines and employment sectors, and the distribution of scientists across combinations of fields and sectors. Model 3 considerably reduces the goodness-of-fit chi-square from 4,903 to 1,085 , but it still does not pass the likelihood ratio test or meet the BIC criterion. Model 4 adds three more terms to the existing model to account for

10. The BIC calculates the goodness of fit in terms of how the data compares to the saturated model. When the BIC is negative, it is considered better than the saturated model (Raftery 1986). Although generally accepted in the literature as a satisfactory measure of a model's goodness of fit, the BIC measure is considerably less stringent than the likelihood ratio test (Weakliem 1999). For this reason, the results of both tests are reported for each of the models. 
the effects of gender on dissemination. This additional factor reduces the goodness-of-fit chi-square (from 1,085 to 891), and significantly improves the fit of the model, but it is not yet a well-fitting model by either LR or BIC criteria. This improvement indicates the presence of differential dissemination trends among the sexes.

Model 5 includes eight additional terms for the three-way interaction between gender, employment sector, and discipline, which accounts for the distribution of women across sectors and sciences. The addition of these terms drastically reduces the goodness-of-fit chi-square, from 891 to 44. With a $p$-value of 0.001 , this model's significance gets closer to, but not above, the 5 percent probability threshold needed to reject the LR test. Model 5 is the first model that achieves a good fit by the BIC criterion $(-177.7)$. The significant increase in fit indicates the importance of accounting for the different locations of men and women when analyzing dissemination. The significance of model 5 suggests that aside from the uneven distribution of scientists across sectors and disciplines (model 3), women scientists have their own unique pattern of location. The tremendous improvement in fit lends powerful support to the sorting mechanism as a primary way in which gender stratification takes place.

Apart from sex distribution, however, disciplines and sectors may have differential effects on men's and women's dissemination. The next two models test whether or not sex disparities change across disciplines or sectors. Model 6 adds two three-way interactions between sex, dissemination, and discipline, and sex, dissemination, and employment sector. This model improves on the previous one with a goodness-of-fit chi-square of 24.8 and 12 degrees of freedom. The significant improvement of this model over the last suggests that there is a differential sex effect operating among disciplines and sectors (to be discussed in more detail later). The model's $p$-value, however, is 0.02 , slightly below the 0.05 threshold needed to reject the LR test. This result indicates that the saturated model-one that includes associations between all variables in the model — is most appropriate for this data. ${ }^{11}$ Model 7 incorporates the saturated model by including an interaction between dissemination, sex, discipline, and employment sector.

Model 7 is the final and best-fitting model of this analysis, indicating that men and women disseminate differently across sectors and disciplines, other things being equal. ${ }^{12}$ Model 7 also documents the persistent presence

11. The significance of the saturated model indicates that a unique relationship exists between all four variables in the analysis, rather than an overarching simpler trend based on combinations of the four. In laymen's terms, this means that sex and dissemination likely vary by discipline and employment sector, concurrently, rather than just discipline or sector alone.

12. Although model 5 is best-fitting by BIC standards, I choose the best-fitting model by the more stringent likelihood ratio test. I make this decision primarily because the BIC criterion, in which models with BIC less than zero are preferred to the saturated model, is far easier to satisfy than the more stringent likelihood ratio test of model fit. In addition, there have been some critiques of the BIC's ability to correctly take into account the sample size of the hypotheses in question (Weakliem 1999). 
of direct sex effects on dissemination. Interaction terms between sex and dissemination activity remain significant in the final model despite accounting for the distribution of women across sciences (model 5) and gendered employment sector and discipline effects on dissemination (models 6 and 7).

Changes in the coefficients for the interaction between sex and dissemination across models are telling. Before controlling for the distribution of women across sectors and sciences, women are more likely to publish than men, and only slightly less likely to engage in dual dissemination. The final model portrays a very different story, one in which women are at a clear disadvantage. The fact that the coefficients become more negative with the addition of sex distribution controls suggests that women tend to be located in sciences and sectors that are less disadvantaging. When controlling for this distribution, however, we see that independent of sector and science, women experience disparities between themselves and their male counterparts.

The final results indicate that the propensity to publish and patent varies with sex as well as discipline and employment sector. Including interactions between (a) sex and dissemination, (b) sex, discipline, and employment sector, and (c) sex, employment sector, and dissemination greatly improve the fit of the model. The models show that the sorting of women across disciplines and sectors is one primary way to account for overall sex disparity in dissemination. Despite accounting for the distribution of scientists across fields, however, the location of scientists alone does not explain patenting and publishing differences between men and women scientists. Furthermore, sex effects on dissemination operate uniquely within disciplines and sectors, and the best fitting model includes interactions between all four variables.

The final model coefficients suggest substantial discipline, sector, and sex effects on dissemination, yet further analysis is needed to discern the relationship among all interactions combined. From these results, it is possible to construct comparisons of log odds across and within groups to investigate the implications of the final model. Table 6.3 presents the log odds and odds ratios of dissemination between men and women across academia and industry, broken down by discipline.

\subsubsection{Odds Ratios}

The raw percentages in the earlier descriptive statistics suggest that gender disparities may vary by employment sector. In particular, industry settings appear to be more gender equal with regard to both patenting and publishing, and industrial women appear to engage in publishing behavior more than industrial men. The loglinear models echo this finding, yet with an important caveat — only for the life sciences. Due to significant, positive interactions between industry, sex, and dissemination, women industrial scientists in the life sciences are equally as likely to publish as men scien- 
Table 6.3 Odds ratios for men and women scientists by employment sector, holding discipline constant

\begin{tabular}{|c|c|c|c|c|c|c|}
\hline & \multicolumn{2}{|c|}{ Life Sciences } & \multicolumn{2}{|c|}{ Engineering } & \multicolumn{2}{|c|}{ Physical sciences } \\
\hline & Academia & Industry & Academia & Industry & Academia & Industry \\
\hline \multicolumn{7}{|l|}{ Publishing only ${ }^{\mathrm{a}}$} \\
\hline Men & 3.705 & 1.430 & 2.272 & 0.066 & 2.584 & 0.777 \\
\hline Women & 3.122 & 1.679 & 5.752 & 0.038 & 3.139 & 0.626 \\
\hline Relative log odds & & & & & & \\
\hline$(\mathrm{M}-\mathrm{F})$ & $0.583 * * *$ & -0.249 & -3.480 & 0.028 & -0.555 & 0.151 \\
\hline Relative odds & $1.791^{* * *}$ & 0.780 & 0.030 & 1.028 & 0.574 & 1.160 \\
\hline \multicolumn{7}{|l|}{ Patenting only } \\
\hline Men & -1.187 & -0.950 & -3.275 & -2.112 & -3.275 & -0.253 \\
\hline Women & -2.809 & -1.110 & -1.349 & -2.917 & -3.575 & -0.796 \\
\hline Relative log odds & & & & & & \\
\hline$(\mathrm{M}-\mathrm{F})$ & $1.622 * *$ & 0.160 & 0.146 & $0.805^{* *}$ & 0.300 & 0.543 \\
\hline Relative odds & $5.063^{* *}$ & 1.174 & 0.146 & $2.237^{* *}$ & 1.350 & 1.721 \\
\hline \multicolumn{7}{|l|}{$\begin{array}{l}\text { Both publishing } \\
\text { and patenting }\end{array}$} \\
\hline Men & 1.926 & 0.730 & 1.181 & -0.196 & 0.705 & 0.741 \\
\hline Women & 0.647 & 0.784 & 3.925 & -0.533 & 0.388 & 0.141 \\
\hline Relative log odds & & & & & & \\
\hline$(\mathrm{M}-\mathrm{F})$ & $1.279 * * *$ & -0.054 & -2.744 & 0.336 & 0.317 & $0.600 * *$ \\
\hline Relative odds & $3.593 * * *$ & 0.950 & 0.060 & 1.399 & 1.370 & $1.820 * *$ \\
\hline
\end{tabular}

Source: National Science Foundation/Division of Science Resources Statistics, Scientists and Engineers Statistical Data System, 1995.

a"Publishing only," "Patenting only," and "Both publishing and patenting" have "Neither publishing nor patenting" as a comparison group.

$* * *$ Significant at the 1 percent level (two-tailed).

**Significant at the 5 percent level.

*Significant at the 10 percent level.

tists. Table 6.3 shows that life science men in academia have approximately 3.6 times higher odds of publishing and patenting than life science women academics $(p<.001)$, but there is no disparity between men and women life scientists in industry. Thus, the models show significant gender disparities among life scientists in the academic sector, whereas men and women industrial life scientists disseminate equally.

Table 6.3 also shows that uniform employment sector effects are not apparent in the other disciplines. Men and women engineering and physical scientists in the academic setting do not exhibit statistically significant sex differences in involvement. The results are similar for industrial engineers, but male physical scientists in industry are approximately 1.8 times more likely to patent and publish than female physical scientists in industry.

Thus, it appears that organizational context plays a significant role in addressing the sex disparity seen in the descriptive statistics in these models. 
In particular, the trends seen in the raw data stem from those exhibited by scientists in the life sciences. Engineers are statistically gender equal with regard to involvement in dissemination activities, and only in industry do men and women physical scientists differ with regard to dual dissemination outcomes.

\subsubsection{Implications of the Survey Models}

The national sample sheds light on the degree to which the sector-level differences seen in my previous research extend beyond the life sciences to other disciplines and sectors. At least on a macro-scale, broad-based sector effects appear to be most prominent for scientists in the life sciences. Why do sex disparities in the life sciences vary so clearly across sector lines? Or conversely, what factors in the academic and industrial settings of engineering, for example, maintain a similar level of sex disparity across sectors?

One way in which the life sciences differ from the physical sciences and engineering is in the proportion of women scientists working in the field. The life sciences have the highest female composition of the science and engineering disciplines in both industry and academia. Previous research has heralded the inroads women have been able to make in the life sciences, and presented it as one of the more women-friendly disciplines. In contrast, women continue to remain a very low proportion of physical scientists and engineers. Whereas the proportion of women in this sample in the life sciences is 27 percent, they make up only 10 percent and 5 percent of the physical sciences and engineering, respectively. The relative equality of men and women in sciences of extremely low female proportion may reflect that, either by choice or necessity, women tend to more closely resemble the men that dictate the norms of their working environments.

I suggest that an additional factor may be important to consider when looking at large scale sector-level effects - organizational form. The structure of industrial firms differs from that of academic settings, and industry context may vary across disciplines as well. Organizational work settings within an industrial sector are not necessarily comparable; they may vary in terms of whether they are more hierarchical or of a "network form" (Powell 1990; Podolny and Page 1998; Smith-Doerr and Powell 2005). Hierarchical companies tend to focus in-house, while network firms engage in durable, yet flexible, ties with external partners. Even the largest network firms are highly relational organizations, embedded in a variety of interorganizational relationships with a diverse mixture of organizational forms - universities, public research institutes, dedicated science-based companies, and large, multinational organizations (Powell, Koput, and Smith-Doerr 1996). In addition, whereas the organization of work in hierarchal companies is bureaucratic and rigidly arranged, network firms exhibit a more horizontal relational organizational structure among scientists. 
Of relevance to this issue is the difference between small firms across disciplines. The life science industry, in particular, is notable for its abundance of small, dedicated biotechnology firms (DBFs) - research-intensive organizations primarily concentrating on genetic engineering and molecular biology for human therapeutic and diagnostic applications (Powell, Koput, and Smith-Doerr 1996). Increasingly, life scientists in industry must decide whether to work for large diversified pharmaceutical corporations or smaller start-up DBF organizations. Biotechnology firms utilize small numbers of employees to leverage connections with other organizations, facilitate the transfer of basic science into new medicines and research tools, and build research connections and alliances with other organizations. For many scientists, the biotechnology setting allows its employees a considerable amount of freedom regarding publishing and basic science activities, and in doing so, facilitates an atmosphere that resembles academic autonomy (Carre and Rayman 1999). Small life science firms, in particular, depend on the development of basic research for new ventures.

Smith-Doerr's research (2004) speaks to the relevance of gender in these two very different industrial work settings. She finds equality in the types of management positions men and women hold in small DBF organizations, but finds greater sex disparities among those in corporate labs and in academia. My additional research with Smith-Doerr using the same sample of life scientists also shows evidence that women perform especially well in these science-based types of organizations (Whittington and SmithDoerr 2008). Women life scientists in industry are equally likely to become involved in patenting activity as industrial men, while male academics are over twice as likely to patent as female life science academics. Importantly, however, the models suggest that this sector difference is limited by type of industrial organization - that is, only in small, dedicated biotechnology firms. Life scientists working in industry for large, multinational companies are not privy to this industry advantage. Thus, the industry effect in this sample mimics that of this previous work. The commercial activity of women scientists located in dedicated life science startups may be driving the sector-level differences seen in the loglinear models.

Clearly there is something unique about industrial DBF work settings. If the culture and organization of scientific work across these varied work settings matters for predicting sex disparities in productivity, the structure of science within smaller, dedicated biotechnology firms may operate as an opportunity structure for sex equality in dissemination. In the next section, I present network visualizations of academic and industrial inventors in biotechnology to examine the structure of science across these two work settings. This structure contains clues to the ways in which the network form may result in a more equitable environment for women scientists. I compile connections among coinventors through U.S. patent activity across a period of two decades, and present network graphs of the scien- 
tific community in both sectors. Investigating collaboration networks provides visual strength to otherwise intangible differences in sector-level structure, and allows for inferences to be made about the degree to which women and men may be affected by critical differences in organizational context. In addition, collaboration networks can address how the structure of informal personal relationships among inventors speaks to the broader arrangement of the production of knowledge across biotechnology firms and the academy.

\subsection{Networks of Collaborations in Public and Private Life Science}

\subsubsection{Data}

The network data consist of inventor-level information from United States patents filed between 1976 and 2002 from the academic and industrial sectors. A list of 482 public and private biotechnology firms from Powell et al. (2005) provided the industry sample of scientists. Powell and colleagues collected the data on firms and firm networks from Bioscan, an industry publication. Bioscan includes nearly the entire population of biotechnology firms in existence between 1988 and 2002 and thus provides a representative sample of industry activity. The academic sample was drawn from Research I universities in the United States. Academic and firm-level data are matched with patent information extracted from the U.S. Patent and Trademark Office (USPTO) database.

I limit the collaboration network to firms and universities in the Boston region. I do so to provide a natural boundary on the scope of the network so as to maintain a manageable size for which to analyze the data. The Boston region is one of the top three areas of regional biotechnology development in the United States. Boston is unique in the sense that, in conjunction with biotechnology firms, its university activity and the activity of other public research organizations (for example, Dana Farber Cancer Institute and Massachusetts Eye and Ear) play a significant role in driving regional biotechnology innovation (Owen-Smith and Powell 2004; Porter, Whittington, and Powell 2005). ${ }^{13}$ For this reason it is useful to analyze the Boston area because of the jointly significant roles that universities and private firms play. ${ }^{14}$

To ensure patent comparability across sector samples, the academic

13. In addition to firm and university inventors, I include collaboration networks of those in public research institutions. Although not the focus of this chapter, the significant role such networks play in the Boston region suggests a more accurate picture of the joint firmuniversity network is achieved with their inclusion.

14. There is a noticeable absence of large multidivisional corporations, such as pharmaceutical companies, in all major biotechnology regions in the United States, including Boston, during this time period (Owen-Smith and Powell 2004). Their lack of presence in the Boston network makes it difficult to ascertain the structure of inventor collaborations in large, 
database is limited to patents in the biotechnology sector. Suitable patent classes were chosen by limiting the university sample to the subclasses that account for the ninetieth percentile and below of life science firm patenting. ${ }^{15}$ In addition to including academic scientists that always patent in biotechnology classes (i.e., scientists for whom all of the patents in their portfolio fall within core biotechnology subclasses), I include all academic scientists that sometimes do (i.e., scientists for whom at least one of the patents in their portfolio is assigned to a core biotechnology subclass). This allows me to make comparisons across scientists who are located in a similar world of science, while limiting unnecessary truncation of scientists' collaborative communities.

I collected inventor names from all patents granted to Boston firms, universities, and public research organizations. Multiple inventions by the same person also involve the confirmation of similar names. Inventions are considered to be from the same person when two inventors match in first, middle, and last name (or part thereof, in the case of missing middle or first names). Importantly, however, two names are only considered a match if they have similar first, middle, and last names and a similar city and state, assignee name, or the same primary and secondary technology class. ${ }^{16}$

It is not possible to obtain from the USPTO information regarding any previous last names an inventor may have had (i.e., maiden names or names changed legally for other reasons), and background searching the list of more than 15,000 name records is not possible. The lack of this information may undercount the patents of women scientists, as they are more likely to change their names than men scientists. My name-matching algorithm addresses this by flagging records for hand coding that match on other criteria but not last name (i.e., combinations of first and/or middle name, assignee, patent class, and/or town). In addition, all hyphenated surnames have been hand coded to search for matches on either name. About 7 percent of the records are hand coded due to flag issues that fall under one of two types - those that are deemed a match yet may not be, or those that are not deemed a match yet may be (name changes fall in this latter type). Flagged records are then hand coded using available information from a variety of publicly searchable sources. ${ }^{17}$

hierarchically-oriented firms such as these. Novartis and Pfizer, however, both moved their R\&D facilities into the Boston area since 2002, no doubt attempting to anticipate benefits from a closer location to such a dominant biotech regional economy. Although not included here, work currently in progress includes these organizations to enable a more fine-grained observation of the differing organizational contexts of industrial work settings.

15. It happens to be the case that these same classes hold the majority of the top patenting classes in university patents.

16. See Whittington (2007) for a more detailed description of the name-matching algorithm.

17. Most record decisions fall into agreement with the algorithm, and the remainder benefit from the hand-coding. This process presents a useful way to manage this data absent the presence of a unique identifier for individuals from the USPTO. 
Inventor gender is coded through the assistance of an algorithm that determines gender based on first name comparisons with a list of names (broken out by gender) from the ninetieth percentile and below of the 1990 U.S. Census. This list contains not only 90 percent of the most common names in 1990, but the cumulative percentage of the U.S. population with each name. In the case where a name appears on both the male and the female list, the cumulative percent for the name in each sex is compared. Names in dispute that are above the seventieth percentile are considered rare, and sex is assigned to the more common sex. ${ }^{18}$ Decisions are not made about androgynous names (i.e., names found on both the male and female list) where a cumulative percentage is not given or jointly rare. There is a tendency in the name-matching algorithm to find matches for a greater percentage of scientists with a typical "American" name, as many foreignbased names are not present in the ninetieth percentile of the U.S. population. Much of the missing data (around 17 percent) lies in names of Indian and Asian descent, both of which are difficult to code for sex. ${ }^{19}$ The missing data is still included (labeled "Sex Unknown") in the network to maintain its integrity.

In the final sample there are sixty-three firms, four universities (Harvard, Tufts, Boston University, and MIT), and thirteen public research organizations (other than the universities) in the Boston area between 1976 and 2002. There are 4,994 inventors who have participated in a total of 5,598 patents from 1976 to 2002; 1,921 inventors have been granted 1,995 patents in biotechnology firms, and 1,174 inventors have been granted 1,246 patents in Boston universities. The Boston firm and university samples contain 26 percent men $(N=411)$ and 20 percent women $(N=199)$, respectively. The proportion of women biotechnology scientists is greater than that in academia or public research organizations (PROs) for each year in the network, although the gap is changing over time as the proportion of women grow in academic and PRO settings. The average yearly percentage female in biotechnology is 24 percent, versus 17 percent in both academia and PROs, respectively.

\subsubsection{Constructing the Network Sample}

The data for this analysis represent two-mode affiliation data, where the inventors are the actors and each patent is the event. In this way, a connection between actors is assumed strictly by their collaboration activity. The

18. When possible, names not on the 1990 census are coded using secondary name data, found in books and websites with downloadable lists of ethnic and foreign names.

19. In their complexity, Indian names are hard to compile into lists of common names. Asian names tend to be androgynous when spelled in English, where gender is typically relayed in tone and written character in those languages. Presumably these missing names contain a similar percentage of men and women to the matched data, although that itself is not knowable. 
affiliation network, when multiplied with its transpose, produces a onemode actor-by-actor network. I refer solely to this one-mode inventorinventor network in this analysis. I focus my analysis of the patent collaboration network on the largest, weakly connected component in a network, which follows the strategy of others in this area (White and Harary 2001; Moody and White 2003). This structure, the main component, represents the greatest concentration of coinventors, and the largest hub of patenting collaboration in the Boston region. ${ }^{20}$

I present network visualizations through the network program Pajek. Pajek produces network images by applying energy-based physical science algorithms that act to minimize node strain based on the inventor ties across the network. I create network images using Pajek's Kamada and Kawai (1989) and Fruchterman and Reingold (1991) energy algorithms. ${ }^{21}$ This two-step process is done first to map and spread the structure of the network, and then to optimize that spread according to the constraints inherent in the node relationships. ${ }^{22}$

\subsubsection{Academic and Industry Patenting Collaboration}

Figure 6.1 is a visualization of the main component of the copatenting network, with 2,371 inventors aggregated across time (1976 to 2002). Circles represent university inventors, squares are biotechnology firms, and triangles are public research organizations. Sex is coded by colorblack nodes are women inventors, gray nodes are men inventors, and white nodes are scientists of unknown sex.

The visualization of the combined network reflects the integration of academic and industrial collaboration networks in the Boston region. The expansive pump of activity in the center of the network represents the commercial side of a lab run by academic Dr. Robert Langer, an MIT professor in the Department of Chemical Engineering who does work at the interface of biotechnology and material science. Robert Langer is unique in the sense that he is world-renowned for his science, as well as his commercial engagement. Forbes, Bio World, Discover, and Time magazines have all independently ranked Langer as a top individual in biotechnology in the United States and the world. His close collaborators are from both university and industry settings, as well as a select few scientists who have moved from MIT to companies, and scientists in a handful of PROs (for more detail on Langer's scientific advisory board and founding connections, see Porter, Whittington, and Powell [2005]). Spreading out from Langer are

20. Visualizations of the main component omit all inventors with no collaboration ties to others, and smaller clusters of collaborators that do not connect to the largest cluster. In this network, there are very few small clusters of collaborators besides the main component.

21. For more information on the algorithms or their use for visualization, see http:// vlado.fmf.unilj.si/pub/networks/pajek.

22. All networks are optimized to account for the number of coinventor ties between scientists. 


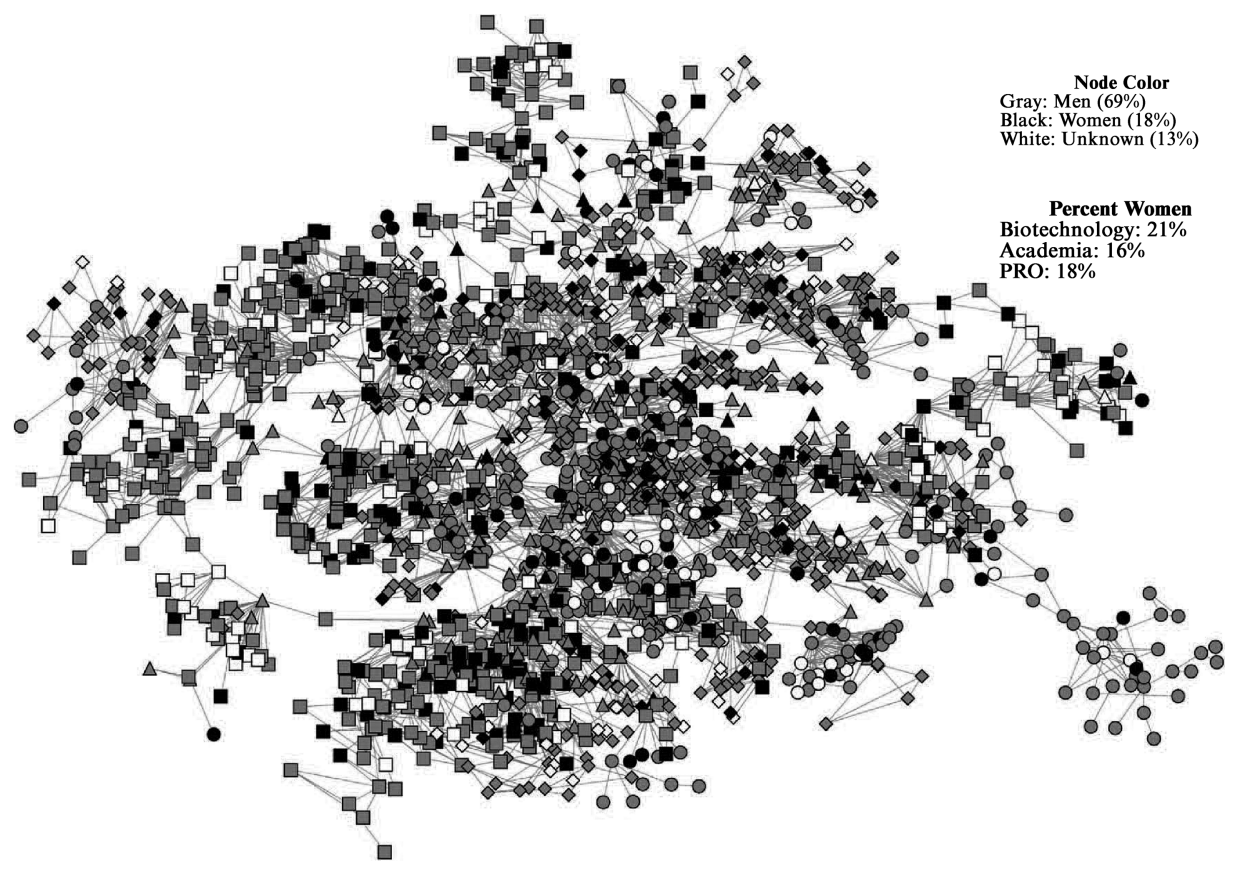

Fig. 6.1 Boston patent coinventor network, main component (1976-2002)

Notes $:$ Circles $=$ University Inventors; Squares $=$ Biotechnology Firms; Triangles $=$ Public Research Organizations.

students, postdocs, and technicians in his lab, other clusters of university lab activity, and several firm and public research organization clusters connected through cross-sector inventors.

Though not the immediate focus of this research, the combined network shows the important role that multivocality plays in linking the two sectors together (Padgett and Ansell 1993; Powell et al. 2005). A select group of 379 (16 percent of the network) scientists have moved across sectors over time or have patents jointly assigned to universities, industry, or public research organizations. These inventors are represented with diamonds. The main component would be vastly unconnected without these inventors. Upon their removal from the network, it essentially dissolves and breaks into almost 200 different clusters - the largest involving only 191 scientists. These scientists are translators in a dual sense - they are familiar with the mores of both university science and science-based companies, and their research translates from the laboratory bench to clinical treatment.

In this analysis, I suggest that differences in the structure of collaborative relations in academia and industry have implications for the ways in which sector-level gender disparities in commercial activity arise. In particular, I focus on the degree of hierarchy in each sector, and discuss (a) how 
the level of hierarchy in an organizational work setting may arise from sector-level goals and supply-side demands of academia and industry, and (b) how these goals and demands interact with men and women scientists embedded in the structure to influence dissemination patterns.

Breaking the full network down by sector, there are distinct clusters of activity within academic and industrial life science. There are four main industrial and three main academic components in the Boston region. Figures 6.2 and 6.3 display the largest components in both the academic and industrial sectors, respectively. The network of collaborations in each of these components has implications for the structure of science in academic and industrial settings, the placement of men and women in these structures, and the level of gender disparity seen in both.

\subsubsection{The Structure of Academic Science}

Figure 6.2 shows the structure of the largest academic component in the Boston university network. This network contains 14 percent women scientists, and is composed mainly of a cluster of MIT scientists, although inventors from Harvard, Boston University, and Tufts are also represented. Langer's laboratory in the center and the activity extending out from the center of the graph are his students and other university professors (MIT and otherwise) and their lab activities.

The structure of academic science resembles that of a bicycle wheel. "Star scientists" are located in the middle of the wheel structure, and collaboration networks extend out from the scientists like spokes. Connections may exist to other wheel-like structures of star scientists, in which collaboration networks again surround the one, central scientist in the center. The structure of academic science reflects the organizational goals of the university. Here, head scientists represent the most central locations, and the domain within which each operates is kept largely separate from other head scientist domains. Networks of academic collaborations are highly centralized, and only a few linkages extend to other centralized networks of collaborations.

The bottom visual in figure 6.2 presents an alternative view of the same academic structure, but organized with the most connected individuals at the top. To scale the figure, I use degree centrality and array the nodes by standard deviation. Those at the bottom level represent scientists who have a degree centrality score that is at the mean of the group or below. Each subsequent level brings the threshold up one standard deviation of degree centrality. At the peak of the figure we find Dr. Langer, whose degree centrality is 18 standard deviations above the mean. When viewed this way, the network suggests that collaborative action among inventors is closely orchestrated through the actions of a few highly influential individuals. In academic science, star scientists reside at the top with limited paths and connections between individuals.

The visualization provides insight into the ways in which scientists' 
A

Men (Gray nodes): $73 \%$

Women (Black): 14

Unknown (White): 12

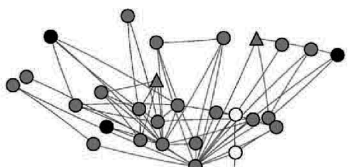

$4^{4} .00$

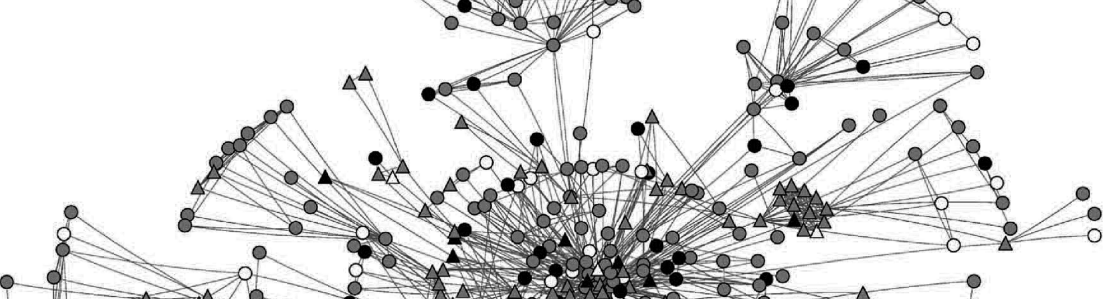

0
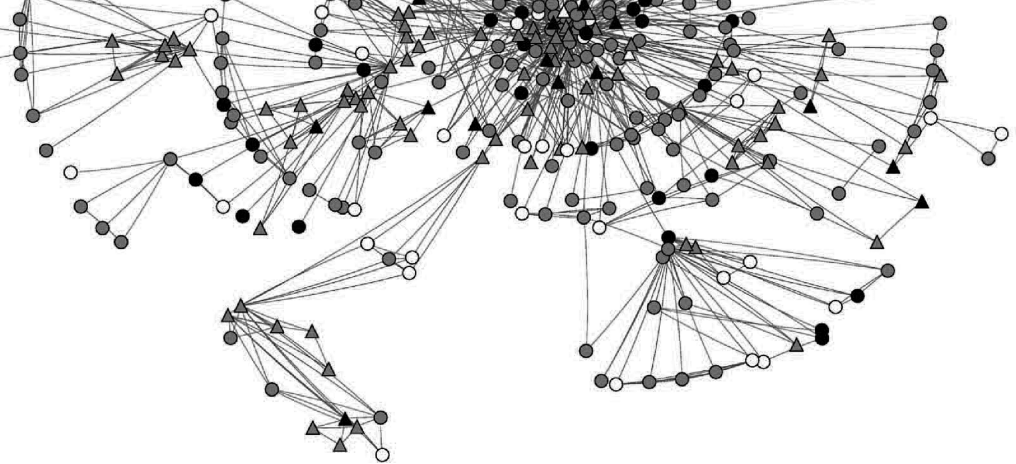

B

Degree Distribution, Normalized

Bottom Level, Average 0.01

Subsequent Levels, Std. Dev.: 0.02

Centralization: 0.28

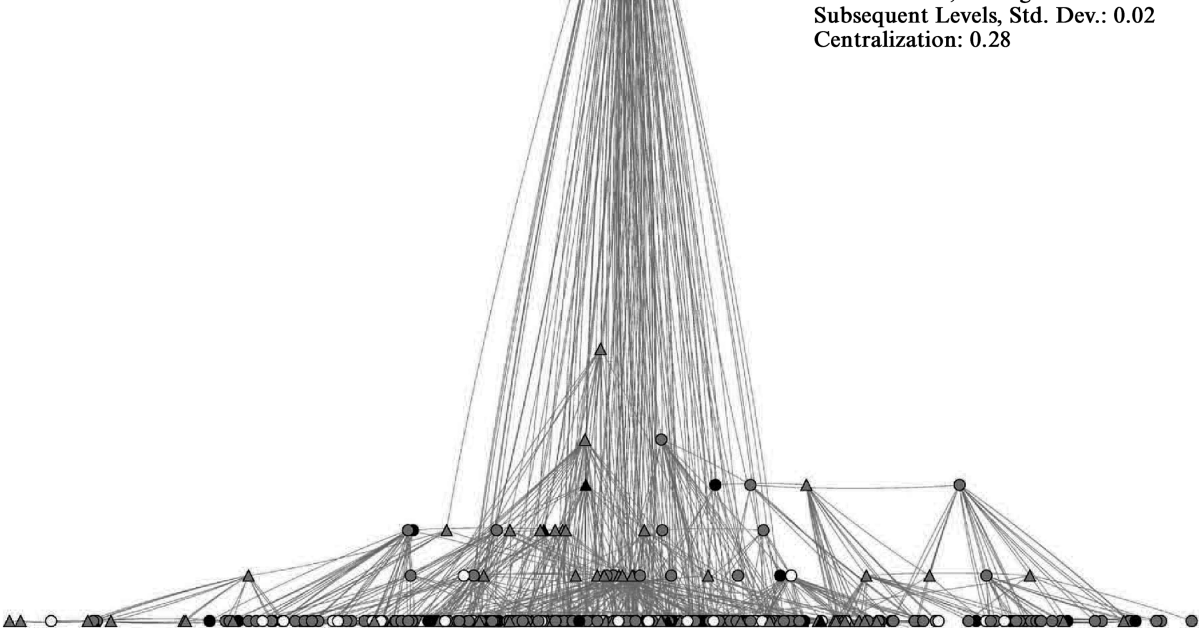

Fig. 6.2 Largest collaboration component, Boston universities (1976-2002): $A$, Network graph; $B$, Degree distribution, normalized.

Notes: Circles $=$ University Inventors; Triangles $=$ Public Research Organizations . 
patenting choices are constrained by and given opportunity through the structure of reward allocation and the normative prescriptions of their social system. In the realm of the academy, reputation, status, and prestige are the reward generators. Recognition for priority and discovery is payment for scientists' labors (Merton 1973). The resulting status order is apparent in this visualization of the academy. This organization also likely reflects the need for academic scientists to facilitate large research projects within labs, and to maintain prestige, offset priority-loss, and maximize economies of scale through connecting to other labs that can provide useful collaboration.

Figure 6.2 also lends insight in how supply-side demands may be shaped by the system. Consider one's location in the Langer hierarchy. Moving or finding opportunities and other resources beyond the Langer cluster may be a difficult task given the single node collaboration connections from which the Langer cluster is linked to other clusters at MIT. In university settings, scientist's ability to appropriate information and reach potential collaborators is limited structurally by the inherent linkages (or lack of them) between clusters. Whether a scientist wants to obtain other collaborators, knows about his or her resource limitations, or is only aware of the difficulty in learning of them yields similar hindrances. Visualizing how scientists are located in the structure of academic science suggests ways to conceptualize how men and women scientists' decisions and actions may interact with the existing structure of academic science.

The overall centralization of the network is a useful way to describe the hierarchy of node distribution in a given system. A simple star network, where everyone is connected to one person but to no one else, has the highest possible degree centralization score of 1 . Centralization measures express the degree of variance in the distribution of central positions across a network as a percentage of a star network of the same size. A network with high degree centralization has few nodes with many ties and many nodes with few ties. In the case at hand, the academic centralization is .28, a high value for a large network. Thus the power of individual actors varies substantially, and positional advantages are unequally distributed in this network. Only a few nodes in academia act as bridges to other groups.

\subsubsection{The Structure of Industrial Science}

Industrial scientists' collaborative arrangements look quite different from that of academic science. Figure 6.3 presents visualizations of the largest connected component in the Boston firm network. The inventors in this component have patented technology developed from a handful of notable biotechnology firms, such as Genetics Institute, Genzyme Corp., Immulogic, and Biogen, among others. In comparison with the main academic component, which has 14 percent female scientists, the industrial component has 25 percent. In addition, we see a clear lack of "star 

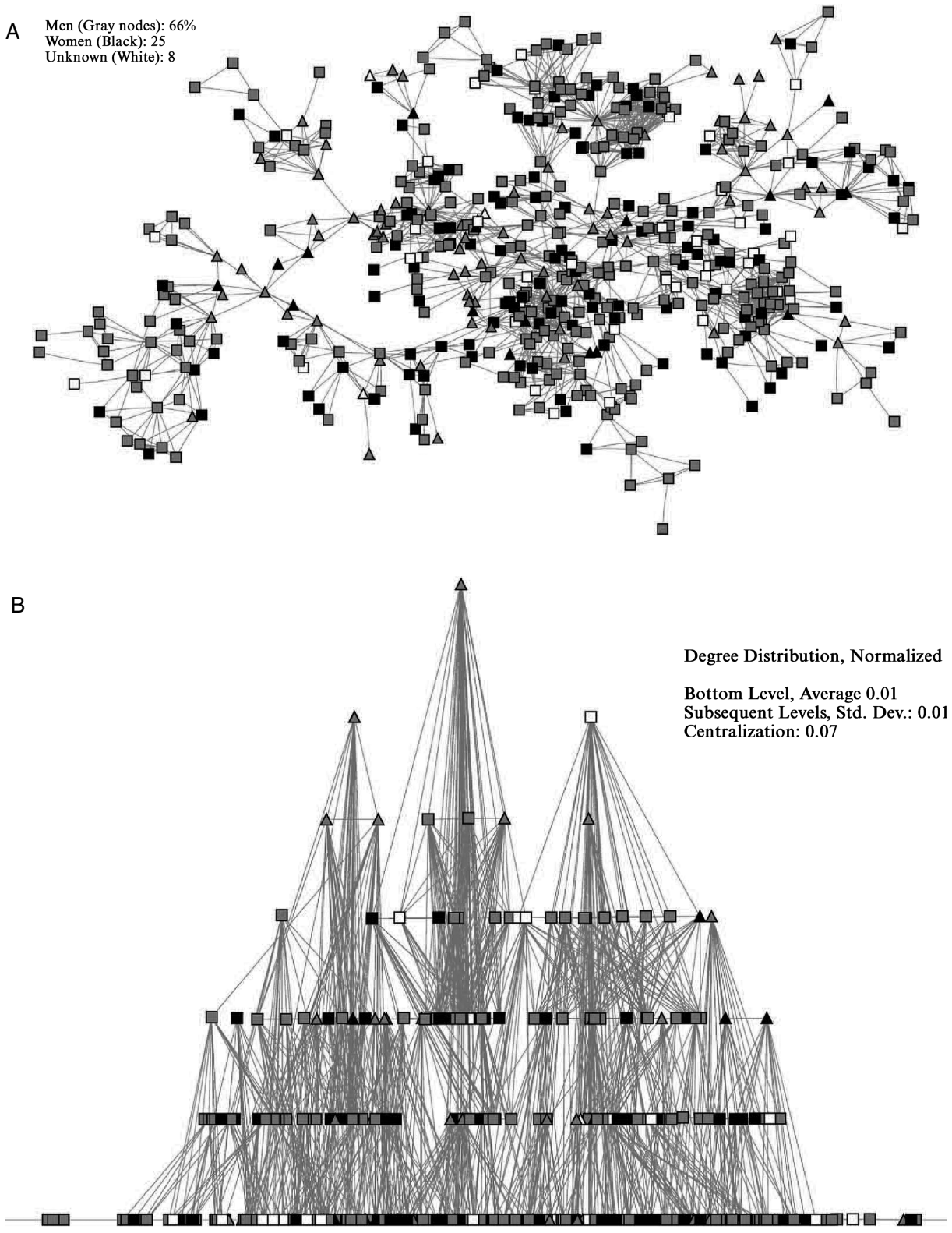

Fig. 6.3 Largest collaboration component, Boston firms (1976-2002): $A$, Network graph; $B$, Degree distribution, normalized.

Notes: Squares $=$ Biotechnology Firms; Triangles $=$ Public Research Organizations . 
scientist" activity, where many nodes are connected to one node but not to others, and an increase in nodes that are reachable through many paths.

The industry visualization exemplifies how collaborative activity reflects commercial goals. Across firms, research collaborations with other companies suggest a flow of ideas and resources across many individuals. Whereas academic scientists are organized around specific labs and top scientists, industrial biotechnology scientists appear to be more uniformly organized, perhaps around research problems or the sharing of information, supplies, and human capital across firms. Like the academic network, figure 6.3 reflects the incentive structure of industrial science.

Figure 6.3 presents the same industry component, but organized hierarchically by degree centrality. The hierarchy in the industry network is more dispersed as compared with the academic network. Instead of all nodes connected to one or two top scientists, in these firms multiple inventors are connected to many other inventors. The graphs suggest that network collaborations may be more fluid in small firm industrial science. The industrial degree centralization is much lower than that of academia, at .07. Thus, academic scientists are arranged in a structure with four times the degree centralization of industrial scientists. In biotech firms, the lack of a star scientist hierarchy speaks directly to the nature of the industrial science system, and has implications for how the supply side of sector activity may shape or be shaped by the structure of industrial science. Because the network is more dispersed hierarchically, scientists may have more collaborative resources to draw from, or more ability to form new research ties within companies. In addition, industrial networks may be less internally competitive than academic ones. In this way, the structure may help to shape the decisions scientists make, and their opportunities for involvement in dissemination.

These figures represent networks of the sum total of ties across all years. By looking aggregately, we see how new and old ties fit into an existing organization of relations among scientists. Equally important, however, is how collaborative activity is organized in real-time slices of available activity - that is, the collaborative opportunities that are present year by year as new ties are made and old ties die out. My additional work on this topic looks at changes in the network structure over time, and finds that across time the academic hierarchy remains, in different capacities, as does the relatively fluid structure of biotechnology (Whittington 2007). This further work also uses the time dynamics of the network to provide evidence of causality relating structural influence to scientists' dissemination outcomes.

\subsubsection{Gender and Network Structure}

The network visualizations suggest that the structure of scientific collaboration closely follows that of the arrangements of work in the academic and industrial organizational forms. A key difference between aca- 
demia and dedicated biotechnology firms is how the structure of knowledge production is organized within each. In the former, the university is arranged around the laboratories of tenured scientists. Collaborators, often graduate students and/or research scientists, are frequently responsible for small pieces of work within the laboratory's focus. The structure of science in this academic setting is such that all research (commercial or otherwise) is tied through the head scientist, and collaborations with others in the lab and across labs with the same focus are often kept to a minimum. Like academic science, in biotech firms there may also be a comparable focus on a specific therapeutic arena. In this setting, however, scientists move from research project to research project within the firm, and are often characterized as "voting with their feet" because of the way they move across and between successful research projects in the organization. ${ }^{23}$

I suggest that the difference between the broadly distributed work of academic science and the more horizontal distribution of knowledge in biotech firms may be important in explaining differences in productivity between men and women within industry and academia. Previous research suggests that women and men create and exist in qualitatively different patterns of interaction within their work setting (Brass 1985; Ibarra 1992; Smith-Lovin and McPherson 1993). Women tend to exist in networks that have more strong relations, and potentially, have access to a fewer number of important bridging, influential ties in their networks. Because industrial settings may be less competitive within firms, or there may be more designated or directed positions of collaboration, women may be better able to access these types of beneficial ties in these settings. Additionally, scientists' position at the confluence of reputation and collaborative networks may just not be as important in industrial settings as they are in academic ones, where scientists' networks can matter greatly to help offset loss through priority-based competition. If this is the case, there may be less of an influence of network position and productivity for scientists in industrial jobs, and differences in men's and women's networks are not as likely to matter as much for research output as in the academy. Thus, gender differences in patenting may be amplified in public versus private settings due to variations in (a) the differing network positions of men and women, and (b) the varying importance of network position on productivity in industry and academia.

My additional work on this topic explores these ideas more fully (Whittington 2007, 2008b). While the graphs show key visual differences, from the network data it is possible to construct standard measures of individual network position and overall network centralization. There are important distinctions between the centrality of men and women across sectors.

23. For an example of this, see the Harvard Business School Case on "planning the unplannable" in Amgen, a large, successful biotechnology firm in Los Angeles, California (Nohria and Berkley 1992). 
My research shows that women in the academy are located in more peripheral and less central collaborative relationships than academic men, and the gender difference in positioning in the academy is significantly larger than in industry. The average yearly male to female ratio of betweenness centrality scores for industry scientists is .96; thus, industry men and women are almost positioned equally central in the network, with women slightly more central. In contrast, the corresponding male to female ratio for academic scientists is 3.1 ; on average men hold positions approximately three times more central than women in the academy. We might expect that variation between academic men and women in the level of betweenness centrality might lead to differentiation in their ability to appropriate further viable research partners and scientific information.

In addition, fixed effects models show that women in biotechnology firms (like men) gain patenting advantages when moving to more central positions that optimize the number of reachable paths to influential others. Women in academia do not see a positive advantage from increasing such connections, but rather see patenting advantages only from increasing their percentage of close ties to others (as do women in industry, and men in both locations). Thus, not only are women achieving less central positions in the academy then men, but they are also benefiting less from those central positions than their counterpart women in other locations. Combined, this work suggests that the structure of academic and industrial science is related to the degree of sex disparity in patenting. One's position in the network matters, but in addition, the structure of one's network also plays a defining role.

\subsection{Conclusion}

The loglinear models confirm that sector-level differences in sex disparities exist in the life sciences, while also showing this discipline to be relatively unique in the level of industrial equality among men and women. I link this industry effect with previous research that suggests the industry effect is located among scientists in the network form-science-based biotechnology firms (Whittington and Smith-Doerr 2008). The research in this chapter provides a structural account for the advantages of these particular locations. The network visualizations show how the structure of science varies across these diverse work settings, and illustrate how men's and women's commercial involvement may be related to their positions within this structure.

Gender differences in involvement within the university may suggest that fewer women have exposure to the commercial process, or alternatively, foster a research focus that lends itself to becoming commercially involved. A more structural explanation for this may be that women lack institutional support for patenting (Murray and Graham 2007), or have 
disadvantageous positions in the collaboration structure of academic science. One factor that has yet to be focused on in other research is the mentor effect in productivity networks. Mentors have been posited to have a significant effect on the commercial orientation of their students, and a strong influence on women scientists (Kram 1988; Fort 1995). In addition, students and their advisors provide many of the cross-sector linkages that knit together academic and industrial networks, thus acting as a key channel for information to diffuse across public and private science. On the individual level, other background factors are important as well, such as scientists' graduate institution, personal abilities, or research focus, and the presence or absence of monetary and other nonpecuniary research support. In particular, my additional research suggests that motherhood is a particularly salient factor predicting patenting by women in the academy (Whittington 2007, 2008a).

A final related and pertinent issue of the network graphs is how the organizational arrangements of large, broadly distributed corporations (such as pharmaceutical firms) are similar or dissimilar from that of dedicated biotechnology firms, as well as the academic life science setting. Elsewhere I have suggested that large corporations may have a similar structure and dynamic to that of university science, and indeed, there are no differences among life science sex disparities among scientists in hierarchical corporations and academic settings (Whittington 2007; Whittington and Smith-Doerr 2008). Including the collaborative activities of scientists in large pharmaceutical firms in future work will help to illuminate how this structure may also contribute to greater gender disparities in commercial involvement.

At the heart of this research is the goal of gaining a better understanding of how work environments and changes in the context of science may make a difference for the known disparities between men and women scientists. With academic participation in both basic science and commercial endeavors on the rise, the fact that female scientists in the academy may lag behind their male counterparts (for whatever reason) and are more comparable to men in industrial settings has significant implications for the future labor market choices of women scientists. In addition, as commercialization becomes more common and has more repercussions for academic scientists, these trends have considerable implications not only for the scientific labor market, but the wider pursuit of knowledge as well.

\section{References}

Aisenburg, N., and M. Harrington. 1988. Women of academe: Outsiders in the sacred grove. Amherst, MA: University of Massachusetts Press. 
Bercovitz, J., and M. Feldman. Forthcoming. Academic entrepreneurs: Social learning and participation in university technology transfer. Organization Science.

Bonaccorsi, A., C. Daraio, and L. Simar. 2006. Advanced indicators of productivity of universities: An application of robust nonparametric methods to Italian data. Scientometrics 66 (2): 389-410.

Brass, D. J. 1985. Men's and women's networks: A study of interaction patterns and influence in an organization. Academy of Management Journal 28 (2): 327-43.

Caplow, T., and R. McGee. 1961. The academic marketplace. New York: Science Editions.

Carre, F., and P. Rayman. 1999. Professional pathways: Examining work, family, and community in the biotechnology industry. Cambridge, MA: Radcliffe Public Policy Institute.

Cohen, W., R. Florida, and R. Goe. 1994. University industry research centers in the United States. Pittsburgh: Carnegie-Mellon University Press.

Cole, J. R. 1979. Fair science: Women in the scientific community. New York: Free Press.

Cole, J., and H. Zuckerman. 1984. The productivity puzzle: Persistance and change in patterns of publication among men and women scientists. In Women in science, ed. M. W. Steinkamp and M. L. Maehr. Greenwich, CT: Jai Press.

. 1987. Marriage, motherhood, and research performance in science. Scientific American 256 (2): 119-25.

Ding, W. W., F. Murray, and T. E. Stuart. 2006. Gender differences in patenting in the academic life sciences. Science 313 (5787): 665-67.

Etzkowitz, H. 1993. Enterprises from science: The origins of science-based regional economic development and the venture capital firm. Minerva 31:326-60.

Etzkowitz, H., C. Kemelgor, and B. Uzzi. 2000. Athena unbound: The advancement of women in science and technology. Cambridge: Cambridge University Press.

Fort, D.C., ed. 1995. A hand up: Women mentoring women in science. Washington, D.C.: Association for Women in Science.

Fox, M. F. 1983. Publication productivity among scientists: A critical review. Social Studies of Science 13 (2): 285-305.

- ed. 1991. Gender, environmental milieu, and productivity in science. New York: W. W. Norton \& Company.

- 2000. Organizational environments and doctoral degrees awarded to women in science and engineering. Women's Studies Quarterly 28:47-61.

. 2001. Women, science, and academia: Graduate education and careers. Gender \& Society 15 (5): 654-66.

Fruchterman, T., and E. Reingold. 1991. Graph drawing by force-directed replacement. Software-Practice and Experience 21:1129-64.

Hall, B. H., A. B. Jaffe, and M. Trajtenberg. 2001. The NBER patent citation data file: Lessons, insights and methodological tools. NBER Working Paper no. 8498. Cambridge, MA: National Bureau of Economic Research, October.

Ibarra, H. 1992. Homophily and differential returns: Sex differences in network structure and access in an advertising firm. Administrative Science Quarterly 37 (3): 422-47.

Kamada, T., and S. Kawai. 1989. An algorithm for drawing general undirected graphs. Information Processing Letters 31 (1): 7-15.

Kleinman, D. L., and S. P. Vallas. 2001. Science, capitalism, and the rise of the "knowledge worker": The changing structure of knowledge production in the United States. Theory and Society 30 (4): 451-92.

Kram, K. 1988. Mentoring at work. New York: University Press of America. 
Long, J. S. 2001. From scarcity to visibility: Gender differences in the careers of doctoral scientists and engineers. Washington, D.C.: National Academies Press.

Long, J. S., P. D. Allison, and R. McGinnis. 1993. Rank advancement in academic careers: Sex differences and the effects of productivity. American Sociological Review 58 (5): 703-22.

Long, J. S., and M. F. Fox. 1995. Scientific careers: Universalism and particularism. Annual Review of Sociology 21:45-71.

Merton, R. K., ed. 1973. Sociology of science. Chicago: University of Chicago Press.

Moody, J., and D. R. White. 2003. Social cohesion and embeddedness: A hierarchical conception of social groups. American Sociological Review 68:103-27.

Morgan, R., C. Kruytbosch, and N. Kannankutty. 2001. Patenting and invention activity of U.S. scientists and engineers in the academic sector: Comparisons to industry. Journal of Technology Transfer 26 (1-2): 173-83.

Murray, F., and L. Graham. 2007. Buying science and selling science: Gender differences in the market for commercial science. Industrial and Corporate Change 16 (4): 657-89.

Nohria, N., and J. Berkley. 1992. Amgen, Inc: Planning the unplannable. Harvard Business School case. 9-492-052.

Owen-Smith, J., and W. W. Powell. 2001. Careers and contradictions: Faculty responses to the transformation of knowledge and its uses in the life sciences. Research in the Sociology of Work 10:109-40.

2004. Knowledge networks as channels and conduits: The effects of spillovers in the Boston biotechnology community. Organization Science 15 (1): 5-21.

Packer, K., and A. Webster. 1995. Inventing boundaries: The prior art of the social world. Social Studies of Science 25 (1): 107-17.

Padgett, J. F., and C. K. Ansell. 1993. Robust action and the rise of the Medici, 1400-1434. American Journal of Sociology 98 (6): 1259-1319.

Podolny, J. M., and K. L. Page. 1998. Network forms of organizations. Annual Review of Sociology 24:57-76.

Porter, K. A., K. B. Whittington, and W. W. Powell. 2005. The institutional embeddedness of high-tech regions: Relational foundations of the Boston biotechnology community. In Clusters, networks, and innovation, ed. S. Breschi and F. Malerba, 261-96. Oxford: Oxford University Press.

Powell, W. W. 1990. Neither market nor hierarchy: Network forms of organization. Research in Organizational Behavior 12:295-336.

Powell, W. W., and J. Owen-Smith. 1998. Universities and the market for intellectual property in the life sciences. Journal of Policy Analysis and Management 17 (2): 253-77.

Powell, W. W., K. W. Koput, and L. Smith-Doerr. 1996. Interorganizational collaboration and the locus of innovation: Networks of learning in biotechnology. Administrative Science Quarterly 41 (1): 116-45.

Powell, W. W., D. R. White, K. W. Koput, and J. Owen-Smith. 2005. Network dynamics and field evolution: The growth of interorganizational collaboration in the life sciences. American Journal of Sociology 110 (4): 1132-1205.

Rabinow, P. 1996. Making PCR. Chicago: University of Chicago Press.

Raftery, A. 1986. Choosing models for cross-classification. American Sociological Review 51:145-56.

Rosenburg, N., and R. Nelson. 1994. American universities and technical advance in industry. Research Policy 23 (3): 323-48.

Smith-Doerr, L. 2004. Women's work: Gender equality vs. hierarchy in the life sciences. Boulder, CO: Lynne Rienner Publishers. 
Smith-Doerr, L., and W. W. Powell. 2005. Networks and economic life. In The handbook of economic sociology, second edition, ed. N. Smelser and R. Swedberg, 379-402. Princeton: Russell Sage Foundation.

Smith-Lovin, L., and M. McPherson, eds. 1993. You are who you know: A network perspective on gender. New York: Aldine de Gruyter.

Stephan, P. E., S. Gurmu, A. J. Sumell, and G. Black. 2007. Who's patenting in the university? Evidence from the survey of doctorate recipients. Economics of Innovation and New Technology 16 (2): 71-99.

Stuart, T. E., and W. W. Ding. 2006. When do scientists become entrepreneurs? The social structural antecedents of commercial activity in the academic life sciences. American Journal of Sociology 112 (1): 97-144.

Ward, K. B., and L. Grant. 1995. Gender and academic publishing. In Higher education: Handbook of theory and research, vol. 11, ed. A. E. Bayer and J. C. Smart, 172-212. New York: Agathon.

Weakliem, D. L. 1999. A critique of the Bayesian information criterion for model selection. Sociological Methods and Research 27 (3): 359-97.

White, D. R., and F. Harary. 2001. The cohesiveness of blocks in social networks: Node connectivity and conditional density. Social Methodology 31:305-59.

Whittington, K. B. 2007. Employment sectors as opportunity structures: The effects of location on male and female scientific dissemination. Ph.D. diss. Department of Sociology, Stanford University. 2008a. Gender and patenting in academia and industry: Interactions between individual and contextual characteristics. Working Paper. Reed College. . 2008b. The influence of network structure on men's and women's scientific collaboration. Working Paper. Reed College.

Whittington, K. B., and L. Smith-Doerr. 2005. Gender and commercial science: Women's patenting in the life sciences. Journal of Technology Transfer 30 (4): $355-70$.

. 2008. Women inventors in context: Disparities in patenting across academia and industry. Gender \& Society 22 (2): 194-218.

Xie, Y., and K. A. Shauman. 1998. Sex differences in research productivity: New evidence about an old puzzle. American Sociological Review 63 (6): 847-70.

- 2003. Women in science: Career processes and outcomes. Cambridge, MA: Harvard University Press.

Zuckerman, H. 1991. The careers of men and women scientists: A review of current research. In The outer circle: Women in the scientific community, ed. H. Zuckerman, J. Cole, and J. Bruer, 27-56. New York: W. W. Norton. 